\title{
Proposing an Environmental Excellence Self-Assessment Model
}

\author{
Peter Meulengracht Jensen, John Johansen, Brian Vejrum Waehrens, \\ and Md. Shewan-Ul-Alam \\ Center for Industrial Production, Aalborg University, Fibigerstaede 10, 9220 Aalborg \\ pmjensen@grundfos.com, $\{j j$, bvw $\}$ aproduction.aau.dk, \\ mshewa11@student.aau. dk
}

\begin{abstract}
This paper presents an Environmental Excellence Self-Assessment (EEA) model based on the structure of the European Foundation of Quality Management Business Excellence Framework. Four theoretical scenarios for deploying the model are presented as well as managerial implications, suggesting that the EEA model can be used in global organizations to differentiate environmental efforts depending on the maturity stage of the individual sites. Furthermore, the model can be used to support the decisionmaking process regarding when organizations should embark on more complex environmental efforts to continue to realize excellent environmental results. Finally, a development trajectory for environmental excellence is presented.
\end{abstract}

Keywords: Environmental Sustainability, Self-Assessment, Global Operations Management.

\section{Introduction}

Not only customers, but also various stakeholders, for example, legislatures, nongovernmental organizations (NGOs) and media, all contribute to the fact that sustainability, especially environmental sustainability, has gradually established itself as a key competitive parameter [1]. Issues such as increasing utility prices, scarcity of resources, and climate changes have caused the environmental sustainability agenda to move into the boardroom [2].

However, several studies report that while companies understand well the philosophy and logic underpinning sustainability (e.g. triple-bottom line and balanced results), few companies manage to incorporate environmental sustainability into organizational practices in a coherent and systematic manner [3]. Environmental sustainability efforts often appear as a hodgepodge of sporadic initiatives without any considerable effect on or contribution to the competitive advantage of the company [4]. This poses a great risk, since companies could lose competitive territory in the globalized economic landscape [1].

\section{Empirical Background and Initiating Problem}

This study is carried out in collaboration with a Danish multinational manufacturing company; a privately owned organization, with sites in more than 45 countries that 
employ $15,000+$ worldwide. The company is considered one of the frontrunners at deploying environmental sustainability. Despite achieving noteworthy environmental results, the case company is similar to others facing difficulties incorporating its efforts systematically. The challenges can be viewed from two perspectives.

From a corporate perspective, there is a need to differentiate efforts and apply more sophisticated solutions at more advanced sites and more basic solutions at more immature sites. There is no "one-size-fits-all" in the global context, yet complete individualization is impossible/inappropriate from a managerial/resource-efficiency point of view.

From a local perspective, there is a need to prioritize and implement the "right" solutions given for the site context and situation and to obtain results that match the resources invested. Management concern is raised whether invested resources match the realized results.

The case company has previously struggled with similar challenges within the field of quality management (QM) and has experienced increases in quality performance by deploying the European Foundation of Quality Management Business Excellence Model (EFQM model) [5], which is now deeply rooted as the overall management framework in the organization.

\section{Theoretical Background}

The EFQM model has been reviewed and revised during the past 20 years [6] and now takes a society-wide perspective on QM and strives to promote "business excellence," that is, improved company-wide performance across the organization, by focusing on customers, people, society and key results [5].

The EFQM model serves as a self-assessment framework to undertake continuous improvement [7] by measuring progress toward the organization's long-term vision and assessing which activities are going well and which have stagnated [8]. In order to do so, the EFQM model consists of the following key elements [5]:

1. Five enabler criteria and four results criteria

2. Definitions and descriptions of the enabler and results criteria

3. A self-assessment approach based on "RADAR" logic

4. A mechanism for quantifying the organization's current state, or "maturity level," and quantifying areas for improvement

\section{$4 \quad$ Research Objective}

Taking the EFQM model as a structural starting point, the objective of this paper is to present and discuss an Environmental Excellence Assessment (EEA) Framework. The purpose of the EEA is to serve as a framework for undertaking continuous improvement activities, to increase environmental performance within the case company, and to overcome managerial challenges previously described. The outlook is that the EEA framework can in future assist similar companies facing similar challenges. This paper briefly presents the EEA model itself in order to provide an overview and then continues to discuss possible scenarios for deploying the model. 


\section{$5 \quad$ Methodology}

This study is part of a three-year research collaboration following a design science approach [9] undertaken as action research [10] and a joint collaboration between the case company and the research institution. The conception of the EEA model is a result of working closely with and within the case company for more than two years, a student MSc-thesis project, and an extensive literature study focusing on environmental sustainability. Furthermore, required inputs to the EEA model conception were provided by a three-day introductory course in the EFQM Business Excellence Model, and presentations, workshops, and discussions with key stakeholders in the case company. The literature study and the stakeholder presentations/workshops served to theoretically and empirically validate the content of the model within the constraints of action research, the embryonic stage of the EEA model development process, and the evolving nature of the environmental sustainability field.

\subsection{Limitations}

This paper does not go into detail describing logical underpinnings for the various criteria and sub-criteria of the EEA. These are presented in table form, to provide the reader an overview. Furthermore, the EEA follows the same principles and approach for self-assessment as the EFQM model. These are not described in this paper. The paper's purpose is solely to discuss prospects for deploying the EEA to solve the challenges facing the case company.

\section{Environmental Excellence Assessment (EEA) Model}

The proposed EEA model consists of five environmental enabler criteria and four environmental results criteria, as depicted in Figure 1. Table 1 provides an overview of EEA model criteria, definitions, and sub criteria.

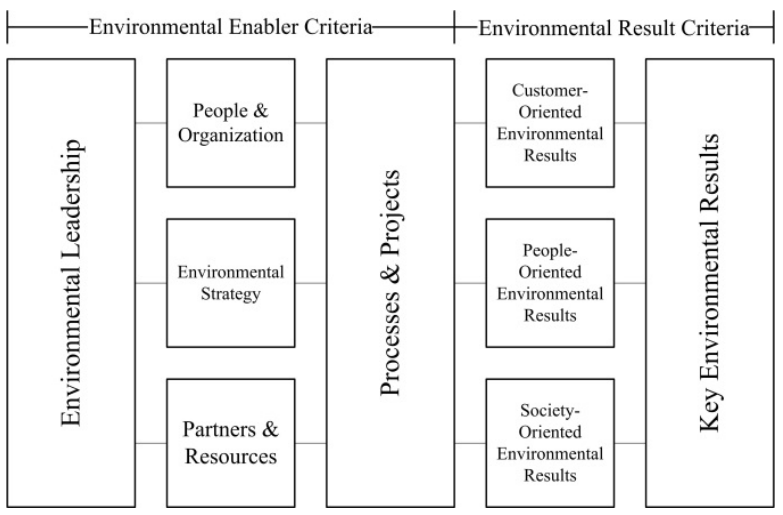

Fig. 1. The EEA Model 
Table 1. Overview of criteria, definitions, and sub-criteria for the EEA model

\begin{tabular}{|c|c|c|c|}
\hline \multicolumn{4}{|c|}{ Enabler Criteria } \\
\hline \multirow{6}{*}{ 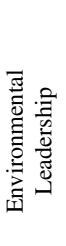 } & \multirow{6}{*}{$\begin{array}{l}\text { Definition } \\
\text { Organizations with excellent environmental } \\
\text { performance have leaders who communicate a } \\
\text { clear purpose for working with environmental } \\
\text { sustainability. They provide a clear direction and } \\
\text { build organizational commitment through } \\
\text { demonstrating the associated business } \\
\text { opportunities. }\end{array}$} & \multicolumn{2}{|c|}{ Sub-Criteria } \\
\hline & & $1 \mathrm{a}$ & Define the vision, purpose, and rationale \\
\hline & & $1 b$ & Environmental management system deployment \\
\hline & & $1 \mathrm{c}$ & Stakeholders engagement \\
\hline & & $1 \mathrm{~d}$ & Reinforce a culture of green thinking \\
\hline & & le & Provide the prerequisites for change \\
\hline \multirow{5}{*}{ 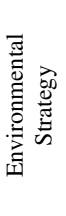 } & \multirow{5}{*}{$\begin{array}{l}\text { Organizations with excellent environmental } \\
\text { performance realize their environmental vision by } \\
\text { implementing an environmental strategy. The } \\
\text { strategy is based on the identification of issues with } \\
\text { significant environmental affect and aligned with } \\
\text { overall business strategy and stakeholder } \\
\text { expectations. }\end{array}$} & $2 \mathrm{a}$ & Embed environmental impact analysis \\
\hline & & $2 b$ & Understand internal strengths/weaknesses \\
\hline & & $2 \mathrm{c}$ & Policy deployment \\
\hline & & $2 \mathrm{~d}$ & Strategy alignment \\
\hline & & $2 \mathrm{e}$ & Strategy communication and implementation \\
\hline \multirow{5}{*}{ 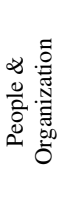 } & \multirow{5}{*}{$\begin{array}{l}\text { Organizations with excellent environmental } \\
\text { performance ensure that their people's } \\
\text { competencies and skills are continuously } \\
\text { developed. They ensure fit between competencies, } \\
\text { resources, and responsibility. They communicate, } \\
\text { care for, reward, and recognize environmental } \\
\text { achievements. }\end{array}$} & $3 \mathrm{a}$ & Competence development \\
\hline & & $3 b$ & Alignment, involvement \& empowerment \\
\hline & & $3 \mathrm{c}$ & "Fit" competence, responsibility \& responsibility \\
\hline & & $3 \mathrm{~d}$ & Constructive communication \& cooperation \\
\hline & & $3 e$ & Reward \& recognition \\
\hline \multirow{6}{*}{ 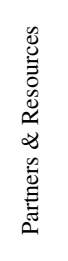 } & \multirow{6}{*}{$\begin{array}{l}\text { Organizations with excellent environmental } \\
\text { performance manage their partners, suppliers, } \\
\text { technological resources, and material flows in order } \\
\text { to implement environmental strategy and increase } \\
\text { their environmental performance. }\end{array}$} & $4 a$ & Supplier and partner management \\
\hline & & $4 \mathrm{~b}$ & Environmental budgets \\
\hline & & $4 \mathrm{c}$ & Building management \\
\hline & & $4 d$ & Technology management \\
\hline & & $4 \mathrm{e}$ & Information technology deployment \\
\hline & & $4 \mathrm{f}$ & Material and utility management \\
\hline \multirow{4}{*}{ 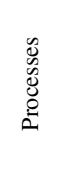 } & \multirow{4}{*}{$\begin{array}{l}\text { Organizations with excellent environmental } \\
\text { performance redesign their processes to improve } \\
\text { environmental performance. This includes } \\
\text { management, business, and support processes. }\end{array}$} & $5 \mathrm{a}$ & Management process redesign \\
\hline & & $5 \mathrm{~b}$ & Business process redesign \\
\hline & & $5 \mathrm{c}$ & Support process redesign \\
\hline & & $5 \mathrm{~d}$ & Project management \\
\hline \multicolumn{4}{|c|}{ Result Criteria } \\
\hline \multirow{4}{*}{ 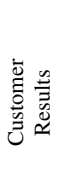 } & Definition & Exa & ples include but are not limited to \\
\hline & \multirow{3}{*}{$\begin{array}{l}\text { Results that put the organization in a better position } \\
\text { to market its products or services. Results are } \\
\text { communicated through appropriate challenges to } \\
\text { customers and stakeholders. }\end{array}$} & & Environmental certification \\
\hline & & & Transparent environmental product data \\
\hline & & & Case stories \\
\hline \multirow{3}{*}{ 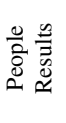 } & \multirow{3}{*}{$\begin{array}{l}\text { Results that demonstrate that the organization has } \\
\text { the commitment of the entire organization and } \\
\text { continuously increases capabilities required to } \\
\text { implement the environmental strategy. }\end{array}$} & & Employee awareness \\
\hline & & & Competence development \\
\hline & & & Managerial acceptance \\
\hline \multirow{3}{*}{ 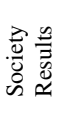 } & \multirow{3}{*}{$\begin{array}{l}\text { Results that demonstrate that the organization } \\
\text { reduces its environmental impact and demonstrate } \\
\text { that they actively strive to go beyond regulatory } \\
\text { compliance. }\end{array}$} & & Organizational reputation \\
\hline & & & Environmental awards \\
\hline & & & Environmental-related media coverage \\
\hline \multirow{4}{*}{ 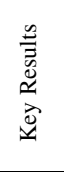 } & \multirow{4}{*}{$\begin{array}{l}\text { Results are a set of environmental performance } \\
\text { indicators that are measurable and that the } \\
\text { organization uses to measure its environmental } \\
\text { performance and associated financial opportunities. }\end{array}$} & & Consumption and cost \\
\hline & & & Payback times on environmental projects \\
\hline & & & Environmental effect on environmental projects \\
\hline & & & Accreditation and certification \\
\hline
\end{tabular}




\section{$7 \quad$ Possible Outcomes of Deploying the EEA Model}

Considering that the EEA model consists of a set of enabler criteria and a set of results criteria, the following four outcomes of its deployment are possible:

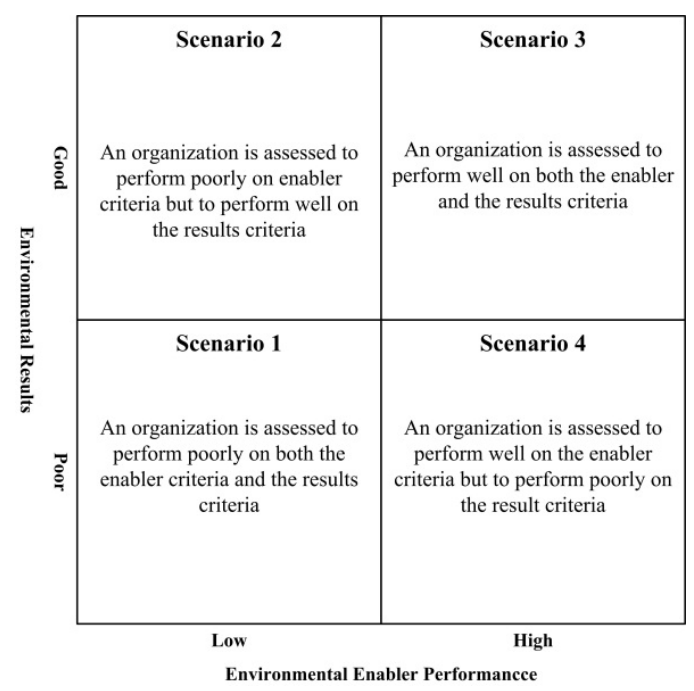

Fig. 2. Possible outcomes for deploying the EEA Model

Based on interaction and discussion with the case company, these four scenarios will be discussed in light of the challenges facing various company sites worldwide.

\subsection{Type 1 Sites: No Integration}

Here, no/few efforts are dedicated to creating environmental results, and as a consequence, environmental performance is lacking. Causes are likely to be rooted in poor performance in leadership (enabler criteria 1) and strategy (enabler criteria 2). It should be evident that there is no management commitment, focus, and direction for working on environmental sustainability. These are considered prerequisites for dedicating resources to work on environmental sustainability and undertaking improvements.

In light of the challenges experiences by the case company, we suggest that corporate and local efforts should be dedicated to forming environmental vision and implementing an environmental strategy for the organization. Furthermore, attention should focus on assistance with deploying a functional environmental management system to serve as a backbone and framework for undertaking environmental tasks.

The next immediate step would be identification of simple "low hanging fruit," from which the organization can generate noteworthy results with little dedicated effort.

\subsection{Type 2 Sites: Project Orientation}

Here, few systematic efforts are taking place, yet the organization achieves noteworthy environmental results. It is likely that this is the result of focusing on 
low-hanging fruit, largely by isolated environmental departments in different locations. Focus is likely to be centered on enabler criteria 4, "partners and resources," for example, through retrofitting buildings and production technology and managing the organization's resources/utility flow.

In this situation, corporate and local efforts should be directed toward continuous identification of environmental improvement projects and, very likely, installation of environmental monitoring systems to identify the next targets to hit.

The next step would be to focus on generating long-term results through process integration, such as analysis and improvement of logistical set-up or the productiondevelopment process. Organizational restructuring will very likely be required to create environmental ownership and responsibility in all relevant processes.

\subsection{Type 3 Sites: Process Orientation}

Here the low-hanging fruits have been harvested, and focus is directed toward process integration and creating the "fit" between competencies, resources, and responsibilities. In order to achieve further results, sites should focus on larger organizational-change initiatives, including competence development, restructuring, and recruitment. This means that attention should be directed toward enabler criteria 3, "people and organization" and 5, "processes and projects." It is likely that the organization still has a large potential for improvement, yet those improvements will come at fairly high investments in terms of capital and resources.

Corporate and local efforts should therefore be directed toward cooperation on these complex change initiatives, which are likely to require changes at several levels in the organization, such as performance metrics, objectives, headcount, process-design, etc.

\subsection{Type 0 Sites: Perplexity}

Here, dedicated and extensive efforts are taking place, yet the results are missing. This is a very unfortunate, but common, situation. It is likely that efforts taking place are scattershot (or a hodgepodge of activities), with little prioritizing based on the situational context of the organization. This scenario has several likely causes. First, lack of sound, integrated leadership and strategy. In addition, ambitions to undertake "high-profile" initiatives with news value and branding potential might cause the organization to down prioritize effective initiatives that hold less or no branding value, so-called "dirty low-hanging fruit."

Corporate and local efforts should be directed toward reviewing organizational leadership and strategy and toward systematically analyzing whether buildings, technologies, etc. have been optimized to support generating environmental results.

\section{Discussion of the EEA Model}

Expected benefits from deploying the EEA are promising, particularly because the EEA model provides insight into which one of the four types each site currently falls into. As mentioned, relevant next steps for the types differ, and the approach, tools, competence requirements, focus, etc. also differ depending on whether the site is a 
Type 1, 2, 3, or 0 . The role of corporate management will differ significantly depending on whether it is striving to assist a Type 1 site, just embarking on integrating environmental sustainability, or a Type 3 site, needing to define how environmental sustainability can provide business value from a strategic and operational procurement perspective.

Furthermore, by deploying the EEA, local management can get an overview of whether to embark on complex, large-scale, business-process re-engineering programs or whether to prioritize efforts to retrofit existing equipment and building technologies.

The intention is that deploying the EEA will yield a more nuanced understanding of the current stage of environmental maturity at individual sites, and, based on that understanding, corporate and local efforts can be customized for each of the four types, thus avoiding both "one-size-fits-all" solutions and myriad individualized solutions.

\subsection{Road-Mapping the Path to Environmental Excellence}

As described in the introduction, most companies struggle to realize results in line with their ambitions and efforts [3] and fail to integrate environmental sustainability strategy with business strategy [4]. Reviewing the four possible site types identified by the EEA has led to the conclusion that one cause of this failure is very likely that these companies find themselves in the perplexing situation faced by Type 0 sites. The EEA provides organizations with a development trajectory, or "path," for realizing environmental results, moving from "no integration" (Type 1) to "project orientation" (Type 2) to "process integration" (Type 3), while avoiding/escaping from "perplexity" (Type 0). Figure 2 depicts this proposed development trajectory, including characteristics of the four types.

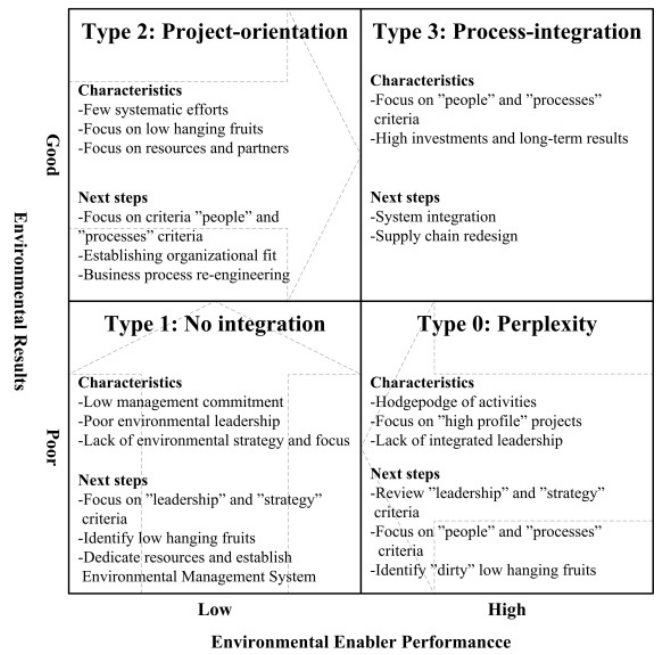

Fig. 3. An environmental excellence development trajectory based on site categorization as a result of deploying the EEA model 


\section{Conclusion and Contribution}

This paper presents an Environmental Excellence Self-Assessment (EEA) model that can help diagnose organizational improvements that need to be undertaken in order to realize environmental results. Prospects for deploying the model are promising, since the EEA model can be expected to provide a nuanced understanding of the current stage of maturity at individual sites. Based on this understanding, corporate and local management efforts can be prioritized in order to implement solutions that will yield results in line with efforts. This paper adds to the body of literature on environmental sustainability and responds to a call made [3 and 11] to move beyond the tool-focused regime and address environmental sustainability as an organizational issue. The paper addresses the issue of how a focused self-assessment on environmental sustainability can be used as a "differentiated management mechanism." The EEA model has yet to be empirically tested, and therefore the validity of the model is fairly low at this embryonic stage of development. However, it is expected that the model will be deployed in the case company in the immediate future and experience will show whether the EEA model lives up to its potential.

\section{References}

1. Porter, M.E., Kramer, M.R.: Strategy \& Society: The Link Between Competitive Advantage and Corporate Social Responsibility. HBR (2006)

2. Pagell, M., Wu, Z.: Building a More Complete Theory of Sustainable Supply Chain ManagementUsing Case Studies of 10 Exemplars. J. of Sup. Chain Man. (2009)

3. Bowen, F.E., Cousins, P.D., Lamming, R.C.: Horses for Courses: Explaining the Gap between the Theory and Practice of Green Supply. Greener Management International (2001)

4. Lubin, D.A., Esty, D.C.: The Sustainability Imperative. HBR (2010)

5. European Foundation for Quality Management, http: / /www. EFQM. org

6. Williams, R., Bertsch, B., Van Der Wiele, A., Van Iwaarden, J., Dale, B.: Self-Assessment Against Excellence Models: A Critique and Perspective. J. Total Quality Management (2006)

7. Boer, H., Chapman, A., Gertsen, F.: CI Changes: From suggestion box to organizational learning. Continuous Improvement in Europe and Australia (2000)

8. Ritchie, D., Dale, B.: Self-assessment using the business excellence model: a study of practice and process. Int. J. of Production Economics (2000)

9. Holmström, J., Ketokivi, M., Hameri, A.: Bridging Practice and Theory: A Design Science Approach. Decision Sciences (2009)

10. Karlsson, C.: Researching Operations Management. Routledge, London (2009)

11. Jensen, P.M., Johansen, J., Wæhrens, B.V.: Pursuing Corporate Sustainability Synergies within a Global Operations Network. In: Proceedings of APMS 2010: Advances in Production Management Systems (2010) 